\title{
The impact of IPP on GTI from the perspective of independent R\&D
}

\author{
Zijie Yang ${ }^{1}$, Dong Huang ${ }^{2}$, Yanzhen Wang ${ }^{3}$ and Yuqing Zhao ${ }^{4}$
}

1 College of Public Administration, Huazhong University of Science \& Technology, 1037 Luoyu Rd., Wuhan 430074, China; yangzijie1996@ foxmail.com.

2 College of Public Administration, Huazhong University of Science \& Technology, 1037 Luoyu Rd., Wuhan 430074, China; hd7269@ hust.edu.cn.

3 School of Economics, Jinan University, 601 Huangpu West Rd., 510632, Gu angzhou, China; suifeng19890903@126.com.

4 College of Public Administration, Huazhong University of Science \& Technology, 1037 Luoyu Rd., Wuhan 430074, China; $1143706765 @$ qq.com.

*Corresondence: hd7269@ hust.edu.cn

Abstract: Due to the continuous trade friction between China and the United States, for domestic enterprises in China, the cost of importing foreign technologies is increasing. Thus, the independent research and development (R\&D) becomes particularly important for the realization of green technology innovation (GTI). This paper establishes a non-linear mediating effect model based on the data of various regions in China from 2012 to 2018. The main results are shown in the following. Firstly, there is an inverted U-shaped relationship between the intensity of intellectual property protection (IPP) and the level of GTI. Furthermore, the independent R\&D investment has a masking effect between them. Secondly, by taking the independent R\&D investment as a threshold variable, we prove our findings. Considering that the intensity of IPP is at a high level in most regions of China, the above statements mean that the enterprises need to continuously increase their investment in $R \& D$, in order to further improve the regional ability in GTI. Meanwhile, local governments should also stimulate enterprises' willingness to expand their scale in $R \& D$ by issuing incentive policies, such as R\&D tax incentives and government subsidies.

KEYWORDS: Intellectual property protection; independent R\&D investment; green technology innovation; masking effect; threshold effect

\section{Introduction}

At present, China is undergoing profound and complex changes caused by the domestic and international environment. In view of the "14th Five Year Plan" period and longer period ahead in China, further development will definitely increase the demand for accelerating scientific and technological innovation. As an important part of the "Five Concepts for Development" proposed by the Chinese government, the research on influencing factors and mechanism of green technology innovation (GTI) is particularly important.

It is generally believed that intellectual property protection (IPP) plays a significant role in technological innovation. Therefore, it can be inferred that there is also a significant relationship between IPP and GTI. Among the previous studies, IPP was mainly regarded as an intermediate variable or threshold variable, in order to 
analyze the regulatory effect or threshold effect of IPP during the process when technological innovation was affected by factors such as environmental regulation, technology introduction and independent research and development (R\&D) investment $[34,37,38]$. The main contribution of this paper is that we take IPP as the core explanatory variable to examine the impact of the intensity of IPP on the level of regional GTI.

As mentioned above, relevant studies have proved that independent R\&D investment and technology import are core factors affecting the level of technological innovation. Therefore, the above factors should be included when analyzing the impact of IPP on GTI.

For domestic enterprises, due to the impact of the continuous trade friction between China and the United States as well as the global epidemic situation, the cost has increased and the purchasing channels have been largely limited while importing foreign advanced technologies. Especially in the field of green technology, there is a big gap between domestic enterprises and their foreign counterparts.

For late developing countries, previous studies have pointed out that the impact of IPP on technological progress depends on the technology gap and the ability to imitate foreign technologies[31], which further shows that the difficulty of technological innovation sharply enhanced with the increase of the intensity of IPP.

In order to cope with this development predicament, while strengthening the protection intensity of core intellectual property rights in China, we should also constantly invest more in independent $R \& D$ to enhance the scale of China's major scientific and technological achievements[20]. Therefore, the enhancement of independent R\&D capability is crucial for improving the level of GTI.

The rest of the paper is organized as follows. In section 2, we review the related literature, propose relevant hypotheses and formulate the research framework. In section 3, we construct the mathematical model, describe the variable in the model and introduce the data source. In section 4, we present and analyze the results of our empirical application. Finally, in section 5 we briefly summarize the results and discuss their implications.

\section{Literature review, hypothesis and framework}

\subsection{The relationship between IPP and GTI}

Existing literatures mainly focus on the relationship between IPP and technological innovation. Most of them believe that IPP plays a positive role in promoting technological innovation[1,38,35]. Some empirical researches have been carried out the interactions among R\&D investment and IPP, which supports the theory that IPP system has incentive effect on innovation output of enterprises[30]. For hightech industries, IPP has significantly promoted their technological innovation[26].

It's also an objective need for China to improve its independent innovation capability by strengthening IPP[20]. For later developing countries, some researches built an endogenous growth model based on the expansion of intermediate product categories. The results showed that the enhancement of IPP could strengthen the 
protection of domestic $R \& D$ achievements, which would finally encourage the technological progress of the country[31].

On one hand, the increase of the intensity of IPP not only inhibits imitation, but also promotes innovation through improving the innovator's profit. On the other hand, the excessive IPP hinders the spread of knowledge, which makes it more and more difficult to accumulate innovation. Some studies have proved that there is an invertedU relationship between IPP and technological innovation[27].

Among literatures focused on the relationship between IPP and GTI, some proposed that it will be helpful to stimulate GTI and improve the green total factor productivity by strengthening the protection of regional intellectual property rights [21].

Furthermore, some studies analyzed the relationship between two-stage efficiency of green innovation and the intensity of IPP. The results showed that the relationship of IPP on green R\&D efficiency is a U-shaped, while the relationship of IPP on the efficiency of achievement transformation is an inverted U-shaped[24].

Based on the above analysis, for the relationship between the intensity of IPP and the level of GTI, we propose the following hypotheses:

Hypothesis 1a. The intensity of IPP significantly promotes the level of regional GTI.

Hypothesis 1b. There is an inverted U-shaped nonlinear relationship between the intensity of IPP and the level of regional GTI.

\subsection{The relationship between IPP and independent $R \& D$ investment}

It is found that stronger IPP can encourage enterprises to increase R\&D investment [2]. The stimulating effect is mainly embodied in the following two aspects.

Firstly, it protects the exclusive rights of innovators within a certain period of time (including time and scope). Thus, with the advantages of monopoly, enterprises which create or own intellectual property rights can obtain more economic benefits and market share. Only in this way can enterprises be willing to invest more in R\&D.

Secondly, by strengthening the IPP, enterprises with weak intention to improve their R\&D capability have to pay high fees to obtain license from the owners. In addition, in many cases, intellectual property owners do not consent to the authorization. Therefore, these enterprises are forced to increase independent R\&D investment in order to minimize the cost. Relevant studies have shown that there is a positive correlation between the intensity of patent protection and the density of R\&D Investment [3,4].

However, with the intensity of IPP increasing, the international technology spillovers effect will be damaged. In other words, imitation will cost more. Meanwhile, independent $\mathrm{R} \& \mathrm{D}$ is the only way for domestic enterprises to grasp the core technology. However, due to the long-term technology gap, it's difficult for domestic enterprises to catch up with their counterparts in developed countries. As a result, domestic enterprises will be eliminated in the fierce market competition, which is not conducive to expanding domestic R\&D investment.

According to this, some scholars reckon that the impact of IPP on R\&D investment is not always positive [5]. There may be both induced effect and crowding out effect $[34,36]$. Some scholars also believe that there is an inverted U-shaped relationship 
between the intensity of IPP and independent R\&D Investment, because the technological level of late developing countries lags far behind that of developed countries [40].

Based on the above analysis, we posit:

Hypothesis 2a. The intensity of IPP is positively correlated with independent R \& D investment.

Hypothesis 2b. There is a nonlinear relationship between the intensity of IPP and independent $\mathrm{R} \& \mathrm{D}$ investment.

\subsection{The relationship between independent $R \& D$ investment and GTI}

A large number of literatures discuss the relationship between $R \& D$ investment and technological innovation. Only a few of them were subdivided into green technology. The capability of GTI includes green product innovation, green process innovation and end-treatment technology. Compared with general technological innovation, GTI can not only produce positive spillover effect, but also internalize negative environmental effect.

There are two main conclusions about the role of R\&D investment in GTI. Firstly, R\&D investment can significantly improve the ability of GTI[6,19]. Based on the DEMATEL model, some scholars have concluded that there are two core factors affecting the ability of GTI of Chinese manufacturing industry. One is the proportion of green $R \& D$ expenditure to total $R \& D$ expenditure, the other is the proportion of green new products to total new products [7].

Secondly, the relationship between R\&D investment and green innovation is nonlinear. Scholars believe that due to the low economic benefit of green environmental protection investment, for the investment in green technology $R \& D$, the endogenous power of enterprise is insufficient [24]. Therefore, with the increase of total R\&D investment, a large amount of funds will flow into the $R \& D$ in non-renewable technology, which is not conducive to GTI [19].

As for the mechanism of the impact of R\&D investment on GTI, relevant researches mainly focus on the government and enterprises. On the one side, some scholars believe that increasing government $R \& D$ investment could reduce the risk cost of innovation subjects, which improves the level of GTI of enterprises[8]. Similarly, the implementation of preferential tax policy on $R \& D$ is benefit for reducing the risk and cost of enterprise R\&D investment. Furthermore, it plays a positive role in promoting green innovation[9]. In addition, government $R \& D$ subsidies are also conducive to improving the efficiency of green innovation in the manufacturing industry[10].

On the other side, researches have proved that $R \& D$ investment in environmental protection of the enterprises is more efficient than that of the government in terms of capital financing and operation[22].

The $R \& D$ expenditures can directly promote the enterprises to accelerate green transformation of traditional technology as well as purchase equipment, software and hardware [20]. 
In addition, the $R \& D$ expenditures guarantee the conditions for training and learning, so as to strengthen the awareness of green innovation, which help equipment and personnel improve the green innovation ability[23].

This paper mainly analyzes the relationship between independent R\&D investment and GTI in terms of IEDS in different regions. Therefore, based on the mentioned literatures, the following hypotheses are proposed:

Hypothesis 3a. Independent R\&D investment significantly promotes regional GTI.

Hypothesis 3b. There is a nonlinear relationship between independent R \& D investment and regional GTI.

2.4 Transmission mechanism of independent $R \& D$ investment on the relationship between IPP and GTI

As for the rationality of the conduction effect of independent R\&D investment, studies have proved that appropriate IPP could promote innovation output and economic growth by increasing independent R\&D Investment[22].

Some scholars take IPP as the threshold variable, and then empirically analyze the threshold effect of independent R\&D on regional innovation capability. On both sides of the threshold, the results show that independent $R \& D$ has a positive impact on improving regional innovation ability. In other words, strengthening IPP can effectively encourage enterprises to expand material capital and human capital investment in R\&D, so as to promote the development of regional innovation capability[38].

Since the models include the square term of the intensity of IPP, the independent $\mathrm{R} \& \mathrm{D}$ investment is taken as the intermediary variable based on above hypotheses.

Hypothesis 4a. Independent R\&D investment has a mediating effect between IPP and GTI.

Hypothesis 4b. Independent R\&D investment has a masking effect between IPP and GTI.

Based on the above four parts of literature review, we found that the existing literatures mainly focused on discussing the impact of IPP or R\&D investment on technological innovation. However, less of them subdivided into the perspective of GTI. For the researches about green technology, most of them focused on the relationship between IPP, R\&D investment and technological innovation, while few of them systematically analyzed the interaction among them at the same time.

Consequently, this paper focuses on the field of GTI. With the help of nonlinear mediating effect model, we innovatively analyze the impact mechanism of IPP and R\&D investment on the level of GTI from the systematical view. And then, we take R\&D investment as an intermediary variable to analyze the intermediate effect of the impact of IPP on GTI.

To sum up, this paper establishs a theoretical framework which is shown in Figure 1. 


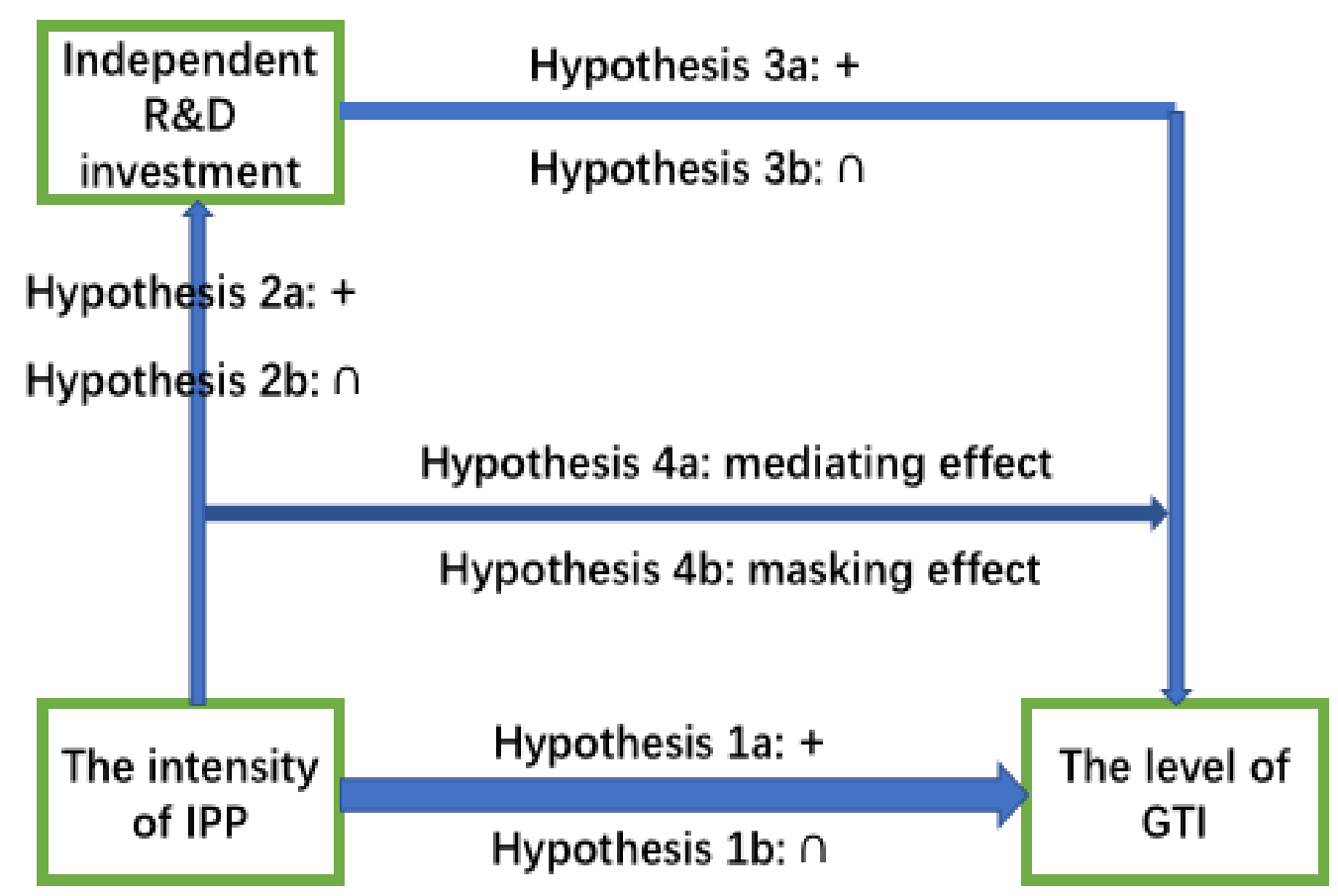

Figure 1. Theoretical framework of this paper.

\section{Materials and Methods}

\subsection{Economic modeling}

According to the step-by-step method proposed by Baron et al. [11], the first step is to test the total effect of IPP on GTI, that is, to verify the rationality of the Hypothesis $1 \mathrm{a}$ and Hypothesis $1 \mathrm{~b}$.

The second step is to test the significance of the product of coefficients. In detail, we firstly test the relationship between IPP and independent R \& D investment, that is to verify the Hypothesis $2 \mathrm{a}$ and Hypothesis $2 \mathrm{~b}$. And then, we analyze the relationship between independent R\&D investment and GTI, which means to verify the Hypothesis $3 a$ and Hypothesis $3 b$.

The third step is to distinguish the mediating effect belongs to complete mediation or partial mediation.

To sum up, three regression models of mediating effect for each test step are established as follows:

$$
\begin{aligned}
& \ln G T I_{i, t}=\theta_{1} \operatorname{lnIP} P_{i, t}+\operatorname{clnIP} P_{i, t}^{2}+\beta_{1} \ln E N S_{i, t}+\gamma_{1} \ln A B C_{i, t}+\varepsilon_{1} \\
& \ln I N D_{i, t}=\theta_{2} \operatorname{lnIPP_{i,t}}+\operatorname{alnIPP_{i,t}^{2}}+\beta_{2} \ln E N S_{i, t}+\gamma_{2} \ln A B C_{i, t}+\varepsilon_{2}
\end{aligned}
$$

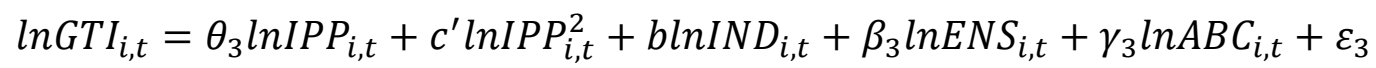

Among the above equations, $\boldsymbol{i}$ represents the regions, $\boldsymbol{t}$ indicates the years. InGTI means the level of regional green technology innovation, $\boldsymbol{I n I P P}$ denotes the intensity of intellectual property protection. $\operatorname{lnIND}$ is set as the investment in independent research and development. $\ln H \boldsymbol{C}$ and $\boldsymbol{I n E N S}$ respectively represent 
human capital and the scale of industrial enterprises above designated size(IEDS). What's more, the error term is presented by $\varepsilon_{1}, \varepsilon_{2}, \varepsilon_{3} \in N\left(0, \sigma^{2}\right)$.

\subsection{Data and variables}

(a) The explained variable is represented by the level of green technology innovation $\left(\boldsymbol{G T} \boldsymbol{I}_{\boldsymbol{i}, \boldsymbol{t}}\right)$. Referring to the method used by some scholars[18], we obtain the data of green patent applications by regions from 2009 to 2018 , so as to characterize the level of green technology innovation.

Specifically, according to the status of green patents application published in China Green Patent statistical report from 2014 to 2017, with the help the patent retrieval platform of the State Intellectual Property Office of P.R. China, we search by the key words which conclude following aspects. Pollution control, pollution control, environmental materials, alternative energy, energy conservation and emission reduction, green agriculture, green forestry, recycling, new energy, green building and green management.

(b) For the core explanatory variable, one indicator is the intensity of the Intellectual property protection $\left(\boldsymbol{I P P} \boldsymbol{P}_{i, t}\right)$, the other is the square term of it $\left(\boldsymbol{I P P} \boldsymbol{P}_{\boldsymbol{i}, \boldsymbol{t}}^{\mathbf{2}}\right)$.

Some methods are mostly used to measure the intensity of IPP, like the GP index, RP index and dummy variable. However, the common disadvantage of these methods is that they only consider the legislative level of IPP, so they are mainly applicable to developed countries with sound judicial systems.

In view of the fact that China is still in the economic and social transition period, the law enforcement is particularly important when measuring the intensity of IPP. Therefore, using the practice of ang et al. for reference[12], this paper takes the ratio of technology market turnover to GDP as an indicator to measure the intensity of IPP.

(c) The independent $R \& D$ investment $\left(\boldsymbol{I N} \boldsymbol{D}_{\boldsymbol{i}, t}\right)$ denotes the intermediate variable. With the gradual progress of the market-oriented reform in China, enterprises have now become the vital innovation entities.

Chinese government also declared that the enterprises should play their main role in technological innovation. Hence, the analysis of independent R\&D investment should be related to the optimal behavior of enterprises' micro entities. In this circumstance, this paper takes the internal $R \& D$ expenditure of the enterprises above designated size as the indicator.

(d) The control variables consist of four parts. According to the data availability and the innovation theory framework proposed by Schumpeter[13], we control other variables which may affect the level of GTI, including the scale of enterprises, human capitals, regions and years.

Based on the Schumpeter Hypothesis, many studies found that there was a close relationship between the scale of enterprises $\left(\boldsymbol{E N} \boldsymbol{S}_{\boldsymbol{i}, t}\right)$ and technological innovation $[13,33]$.

Large-scale enterprises have tremendous capital strength and mature internal control measures, which can guarantee continuous and diversified investment in GTI [20]. Meanwhile, large-scale enterprises have significant advantages in market share, 
which is conducive to reducing the cost of green products for adapting to the market and improving the efficiency of achievement transformation[14]. In this paper, to characterize the scale of enterprises, the logarithm of the total assets at the end of the period of the IEDS.

Human capital $\left(\boldsymbol{H} \boldsymbol{C}_{\boldsymbol{i}, \boldsymbol{t}}\right)$ is the main body of organizational learning, and also the source of creativity and new knowledge. Through knowledge creation, collision and transfer, it could influence innovation output and perform a decisive function in technological innovation [17]. Therefore, this paper uses the full-time equivalent of R\&D personnel of the IEDS to measure the human capital in each region.

\subsection{Data source}

Because there are many missing values in Tibet, Hainan and Qinghai, the data of them will be eliminated in the empirical analysis. It should also be noted that, since 2011, for the IEDS, the statistical scope of has been adjusted from the corporate industrial enterprises with annual main business income reaching more than 5 million yuan to 20 million yuan or more. In order to maintain the statistic caliber consistency and the data availability, we analyze the data of 28 provinces and autonomous regions (excluding Hong Kong, Macao and Taiwan) from 2012 to 2018.

Among them, the data of green patent is obtained from the patent retrieval platform of the State Intellectual Property Office of P.R. China. The data of regional GDP and technology markets turnover are obtained from the annual China Statistical Yearbook.

For the IEDS in each region, the data of final total assets are obtained from the annual data on the website of the National Bureau of Statistics of China. Furthermore, the full-time equivalent of the internal R\&D expenditure and personnel comes from the annual China Statistical Yearbook on Science and Technology.

In order to avoid the possible heteroscedasticity in the model, we take the natural logarithm of all variables in each model.

\section{Empirical results}

\subsection{Descriptive statistics}

The correlation coefficient matrices were calculated for each variable in model (1) $\sim(3)$. And the results are shown in Table 1.

Table 1. Results of correlation coefficient matrix and descriptive statistics.

\begin{tabular}{|c|c|c|c|c|c|c|}
\hline & $\ln G T I_{i, t}$ & $\operatorname{lnIPR_{i,t}}$ & $\ln I P R_{i, t}^{2}$ & $\operatorname{lnIN} D_{i, t}$ & $\ln E N S_{i, t}$ & $\ln H C_{i, t}$ \\
\hline \multicolumn{7}{|l|}{$\ln G T I_{i, t}$} \\
\hline $\operatorname{lnIPR_{i,t}}$ & $\begin{array}{c}0.2929 * * \\
*\end{array}$ & & & & & \\
\hline $\ln I P R_{i, t}^{2}$ & $\begin{array}{c}0.2290 * * \\
*\end{array}$ & $\begin{array}{c}0.9592 * * \\
*\end{array}$ & & & & \\
\hline $\ln I N D_{i, t}$ & $\begin{array}{c}0.8498 * * \\
*\end{array}$ & 0.0903 & 0.0404 & & & \\
\hline $\ln E N S_{i, t}$ & $\begin{array}{c}0.7803 * * \\
*\end{array}$ & 0.1044 & 0.0919 & $\begin{array}{c}0.9011 * * \\
*\end{array}$ & & \\
\hline
\end{tabular}




\begin{tabular}{c|c|c|c|c|c|c}
\hline $\ln H C_{i, t}$ & $\begin{array}{c}0.7969 * * \\
*\end{array}$ & 0.0467 & 0.0092 & $\begin{array}{c}0.9768 * * \\
*\end{array}$ & $\begin{array}{c}0.8749 * * \\
*\end{array}$ & \\
\hline Mean & 5.498507 & 0.0143 & $\begin{array}{c}0.00097 \\
9\end{array}$ & 14.5076 & 10.23197 & $\begin{array}{c}10.8385 \\
2\end{array}$ \\
\hline Std. & 1.163113 & $\begin{array}{c}0.027910 \\
3\end{array}$ & $\begin{array}{c}0.00413 \\
1\end{array}$ & 1.114561 & 0.669644 & $\begin{array}{c}1.12563 \\
4\end{array}$ \\
\hline Minimum & 2.079442 & $\begin{array}{c}0.000193 \\
6\end{array}$ & $3.75 \mathrm{e}-08$ & 11.87545 & 8.488832 & $\begin{array}{c}8.34188 \\
7\end{array}$ \\
\hline $\begin{array}{c}\text { Maximu } \\
\mathrm{m}\end{array}$ & 8.334472 & $\begin{array}{c}0.160160 \\
5\end{array}$ & $\begin{array}{c}0.02565 \\
1\end{array}$ & 16.86346 & 11.73033 & $\begin{array}{c}13.3406 \\
2\end{array}$ \\
\hline
\end{tabular}

Note: $* * * \mathrm{p}<0.01 ; * * \mathrm{p}<0.05 ; * \mathrm{p}<0.1$.

Table 1 shows the main statistical characteristics of each variable. The mean value of the intensity of IPP is 0.014 , but there are huge differences between regions. The maximum observed value is 0.16 , which represents the intensity of protection of Beijing in 2017. Furthermore, the correlation coefficients between the GTI and other variables are all significant.

\subsection{Nonlinear mediating effect test}

Scholars reckoned that methods of testing the mediating effect, like Baron's, may distort the inverted U-shaped relationship[15]. Thus, they can't clearly reveal the mediating effect of the variables between independent and dependent variables.

Therefore, this paper uses the process for the bootstrap mediation test proposed by some scholars [30]. In order to estimate the parameters in the model.

At first, we did the Hausman test of model (1) (3). The results show that the fixed effect model is more suitable than the random effect model. Therefore, this paper establishes double fixed effect model to estimate the coefficients in these models respectively. The estimated results are shown in Table 2.

Table 2. Results of fixed effect regression of each model by stepwise method

\begin{tabular}{|c|c|c|c|}
\hline & \multicolumn{2}{|c|}{$\ln G T I_{i, t}$} & $\ln I N D_{i, t}$ \\
\hline & Model(1) & $\operatorname{Model}(3)$ & $\operatorname{Model}(2)$ \\
\hline \multirow{2}{*}{$\ln I P R_{i, t}$} & 4.03793 & 6.17841 & -2.561906 \\
\hline & [8.113102] & [8.486172] & [3.219342] \\
\hline \multirow{2}{*}{$\ln I P R_{i, t}^{2}$} & $-50.9187 *$ & $-56.2644 * *$ & 6.398181 \\
\hline & [28.02858] & [26.80536] & [12.04919] \\
\hline \multirow{2}{*}{$\ln E N S_{i, t}$} & 0.1592163 & -0.0711767 & 0.2757537 \\
\hline & [0.3490089] & [0.2037269] & [0.2229734] \\
\hline \multirow{2}{*}{$\ln H C_{i, t}$} & $0.3160493 * *$ & -0.259422 & $0.6887719 * * *$ \\
\hline & [0.146455] & {$[0.1688583]$} & [0.057358] \\
\hline \multirow{2}{*}{$\ln I N D_{i, t}$} & & $0.8355033 * * *$ & \\
\hline & & [0.1949472] & \\
\hline \multirow{2}{*}{$\begin{array}{c}\text { Time-fixed effect } \\
\text { Region-fixed } \\
\text { effect }\end{array}$} & YES & YES & YES \\
\hline & YES & YES & YES \\
\hline \multirow{2}{*}{ cons } & -0.3125978 & -3.689719 & $4.04202 * *$ \\
\hline & [3.311663] & [2.78505] & [1.909788] \\
\hline
\end{tabular}



$R^{2}$
0.6678
0.7577
0.9647

Observations

196

196

196

Note: $* * * \mathrm{p}<0.01 ; * * \mathrm{p}<0.05 ; * \mathrm{p}<0.1$. Standard errors in parentheses.

It can be seen from table 2 that the coefficient $c$ corresponding to the square term of the intensity of IPP in model (1) and the coefficient $\boldsymbol{c}^{\prime}$ corresponding to the square term of the intensity of IPP in model (3) are both significantly negative. Therefore, the Hypothesis 1a is rejected and the Hypothesis $1 \mathrm{~b}$ is verified. By testing the significance of the product of coefficients, we can obtain the following conclusions.

The coefficient $\boldsymbol{\theta}_{\mathbf{2}}$ corresponding to the intensity of IPP in model (2) is negative but not significant, so it refuses the Hypothesis 2a. The coefficient $\boldsymbol{a}$ corresponding to the square term of the intensity of IPP is negative but not significant, so the Hypothesis $2 b$ is refused.

The coefficient $\boldsymbol{b}$ in model (3), corresponding to independent R \& D investment, is significantly positive. Hence, the Hypothesis $3 \mathrm{~b}$ is rejected while the Hypothesis $3 \mathrm{a}$ is verified. At this time, the model satisfies the premise condition of the bootstrap test, in other words, at least one coefficient is not significant.

Secondly, with the help of the measurement software, the bootstrap method is used to test $\boldsymbol{H}_{\mathbf{0}}: \boldsymbol{a b}=\mathbf{0}$. The results are shown in Table 3 .

Table 3. Results of Mediating effect test

\begin{tabular}{c|c|c|c|c|c|c|c|c}
\hline & \multicolumn{3}{|c|}{$\begin{array}{c}\text { Correlation coefficient of } \\
\text { the mediating effect }\end{array}$} & \multicolumn{2}{c|}{$\begin{array}{c}\text { confidence interval } \\
\text { of } 95 \%\end{array}$} & \multicolumn{2}{c}{$\begin{array}{c}\text { bias-corrected } \\
\text { confidence interval } \\
\text { of 95\% }\end{array}$} \\
\cline { 2 - 8 } & coefficient & $\begin{array}{c}\text { Bootstrap } \\
\text { standard } \\
\text { error }\end{array}$ & $\mathrm{Z}$ & $\mathrm{P}$ & $\begin{array}{c}\text { Lower } \\
\text { limit }\end{array}$ & $\begin{array}{c}\text { Upper } \\
\text { limit }\end{array}$ & $\begin{array}{c}\text { Lower } \\
\text { limit }\end{array}$ & $\begin{array}{c}\text { Upper } \\
\text { limit }\end{array}$ \\
\hline $\begin{array}{c}\text { Indirect } \\
\text { effect }\end{array}$ & $6.091 * *$ & 3.004 & 2.03 & 0.043 & 0.201521 & 11.98049 & 0.61763 & 12.93508 \\
\hline $\begin{array}{c}\text { Direct } \\
\text { effect }\end{array}$ & $49.63 * * *$ & 3.135 & 15.83 & 0.000 & 43.48449 & 55.77611 & 43.7703 & 55.64542 \\
\hline
\end{tabular}

Note: $* * * \mathrm{p}<0.01 ; * * \mathrm{p}<0.05, * \mathrm{p}<0.1$. Bootstrap sampling counts 500 times.

Table 3 shows that the indirect effect is positive. The confidence interval of $95 \%$

is $[0.201521,11.98049]$ which excludes zero, indicating that the mediating effect is significant. In addition, for the square term of the intensity of IPP, as is shown in Table 1, the coefficient $\boldsymbol{c}^{\prime}$ is significantly negative. That is, the direct effect is significant.

Comparing to $\boldsymbol{c}^{\prime}$, the coefficient $\boldsymbol{a b}$ is in the opposite direction. In this case, it can be concluded that independent R\&D investment has a masking effect on the relationship between IPP and GTI. Meanwhile, the Hypothesis $4 \mathrm{~b}$ is verified. We can also calculate, for the ratio of indirect to direct effect, the absolute value is 0.108 .

Based on the results of the fixed effect regression model and non-linear mediating effect test, we find that the relationship between the intensity of IPP and the level of GTI is an inverted U-shaped. That is consistent with the conclusions of most literatures.

We find that the independent $R \& D$ investment, as an intermediary variable, plays a masking role on the total effect. That is one of the differences between this paper and 
other existing literatures. In other words, after excluding the positive impact of independent R\&D investment on GTI, the inverted U-shaped effect of IPP on GTI becomes greater. This situation can occur because we examine the nonlinear relationship between the intensity of IPP and GTI. That's to say, the masking effect of independent $R \& D$ investment mainly represents the impact on the quadratic term of the intensity of IPP. At the same time, as relevant studies have also proposed, the inverted U-shaped relationship between the intensity of IPP and technology growth rate corresponds to the specific technology development stage.

With the continuous increase of the independent R\&D investment in China, the negative effect of IPP on independent innovation will also be weakened [39]. Currently, various regions in China are strengthening the intensity of IPP. In this circumstance, it can be concluded that the non-linear relationship between IPP and GTI, especially the negative effect, will be impacted if the scale of independent R\&D investment keeps growing.

\subsection{Threshold effect test}

By using the Hansen threshold regression model [16], we analyzes the nonlinear relationship between the interpreted variable, the core explanatory variable and the intermediate variable in order to test the robustness of the results.

Hansen's nonlinear panel threshold regression model could automatically identify the sample data, better capture the nonlinear threshold characteristics caused by structural mutation in economic system. Therefore, it's more objective and accurate in dealing with the nonlinear problems which have structural changes [26].

In accordance with the mediating effect test, the number of green patents is also selected as the dependent variable. The enterprise scale, human capital, time and region effect are the control variables. The independent $R \& D$ investment is taken as the threshold variable. Table 4 shows the results obtained from repeated sampling 100 times by the bootstrap method.

Table 4. Results of threshold effect test

\begin{tabular}{cccccccc}
\hline & $\begin{array}{c}\text { Threshold } \\
\text { value }\end{array}$ & $\begin{array}{c}\text { Residual } \\
\text { sum of } \\
\text { squares }\end{array}$ & $\begin{array}{c}\text { Mean } \\
\text { square } \\
\text { error }\end{array}$ & $\begin{array}{c}\mathrm{F} \\
\text { statistic }\end{array}$ & $\begin{array}{c}\mathrm{P} \\
\text { value }\end{array}$ & $\begin{array}{c}\text { Lower } \\
\text { boundary }\end{array}$ & $\begin{array}{c}\text { Upper } \\
\text { boundary }\end{array}$ \\
$\begin{array}{c}\text { Single } \\
\text { threshold }\end{array}$ & 13.9918 & 12.6579 & $\begin{array}{c}0.067 \\
0\end{array}$ & 20.15 & 0.040 & 13.9863 & 14.0288 \\
\hline
\end{tabular}




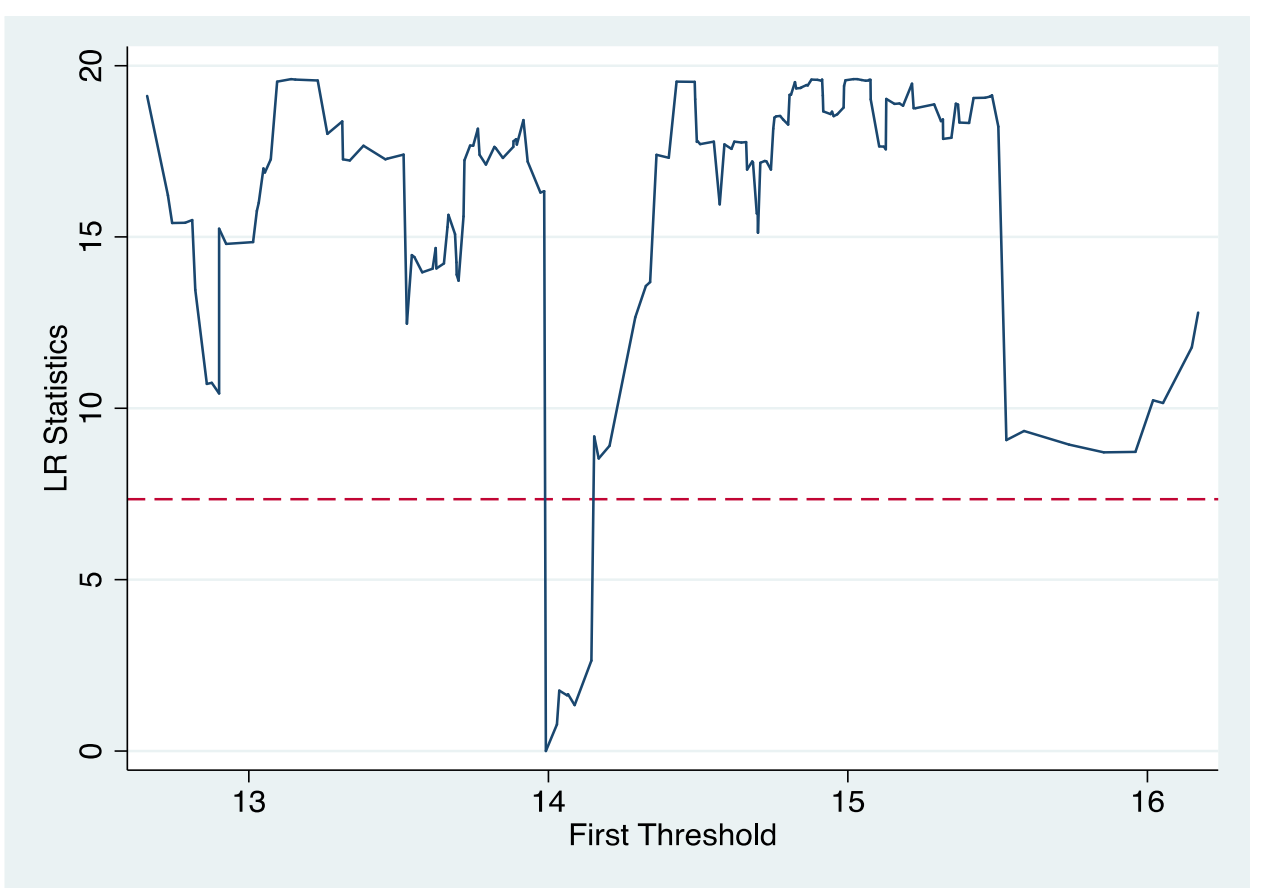

Figure 2. Results of single threshold test

Figure 2 gives the results of the threshold test, where the abscissa presents the single threshold value and the ordinate presents the value of LR statistics. Combined with table 4 and Figure 2, it can be seen that the threshold effect is significant, which proves that the model has a single threshold. Therefore, the threshold regression model can be established as follows:

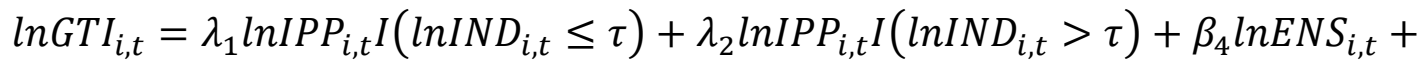

$$
\begin{aligned}
& \gamma_{4} \ln H C_{i, t}+\rho X_{i, t}+\varepsilon_{4}
\end{aligned}
$$

As is shown in Equation (4), the core explanatory variable is represented by the intensity of intellectual property protection $\left(\ln I P P_{i, t}\right)$, while independent $\mathrm{R} \& \mathrm{D}$ investment $\left(\ln I N D_{i, t}\right)$ is set as the threshold variable. $X_{i, t}$ denotes the time and region control variables, $\tau$ indicates the threshold value, $I(\cdot)$ represents the indicator function. Thus, when the group boundary point is unknown, the threshold model is essentially equivalent to the grouped regression model.

For the threshold regression model, the original hypothesis is $H_{0}: \lambda_{1}=\lambda_{2}$. If the original hypothesis proved valid, in other words, there is no threshold effect. That is, the relationship is linear between the threshold variables and the explained variables. Taking the threshold value 13.9918 as the cut-off point, fixed effect grouped regression was performed on Equation (4). The results are shown in Table 5.

Table 5. Results of fixed effect grouped regression

\begin{tabular}{ccc}
\hline & \multicolumn{2}{c}{$\ln G T I_{i, t}$} \\
\cline { 2 - 3 } & Grouped regression & Grouped regression \\
& $\left(\ln I N D_{i, t} \leq 13.9918\right)$ & $\left(\ln I N D_{i, t}>13.9918\right)$ \\
$\ln I P P_{i, t}$ & $15.7696^{*}$ & -0.6976966 \\
$\ln E N S_{i, t}$ & {$[8.330952]$} & {$[4.609653]$} \\
& 1.189778 & -0.0722301 \\
\hline
\end{tabular}




\begin{tabular}{ccc}
\hline & {$[0.5244002]$} & {$[0.1725189]$} \\
$\ln H C_{i, t}$ & -0.0498747 & $0.6614532 * * *$ \\
Time-fixed effect & {$[0.1854032]$} & {$[0.1667284]$} \\
Region-fixed effect & YES & YES \\
Intercept & YES & YES \\
Observations & -6.984326 & -1.305194 \\
\hline
\end{tabular}

Note: $* * * \mathrm{p}<0.01 ; * * \mathrm{p}<0.05, * \mathrm{p}<0.1$. Standard errors in parentheses.

According to the results in table 5, when the value of the independent $R \& D$ investment is lower than 13.9918, there are 13 qualified regions where the intensity of IPP has a significant positive effect on GTI. This conclusion indicates that the level of regional GTI has been continuously improved, due to the strengthening of IPP in the early years.

When the independent R\&D investment has crossed the threshold, 20 regions match the conditions. At this time, the effect of the intensity of IPP on the level of GTI becomes negative, which verifies the rationality of Hypothesis $1 \mathrm{~b}$. However, it should be noted that the effect coefficient is not significant. The possible reasons are as follows:

Firstly, as is mentioned in the results of mediation effect test, independent R\&D investment has a masking effect on the impact of the intensity of IPP on the level of GTI. Therefore, the significant inverted U-shaped relationship in model (1), which is shown in Table 2, will be impacted. In addition, in recent years, China has continuously strengthened its independent R\&D and innovation.

Secondly, considering data availability and statistic caliber consistency, we only select relevant indicators of various regions which are ranged from 2012 to 2018 . Thus, the latest data cannot be updated in time, which may cause the insignificant result.

At the same time, for regions with high level of independent R\&D investment, the results in Table 5 also show that human capital has a significant positive impact on local GTI.

\section{Conclusions}

Previous studies have paid more attention to the relationship between IPP and technological innovation, while less of them involved in the field of GTI. The scanty literatures often ignored the role of independent $R \& D$.

In order to investigate the mediating effect of independent $R \& D$ between the intensity of IPP and the level of GTI, this paper collects panel data of 28 regions in China from 2012 to 2018.

Based on the results of nonlinear mediating effect test and threshold regression, we obtain the following conclusions.

Firstly, as a whole, there is an inverted U-shaped nonlinear relationship between the intensity of IPP and the level of GTI in China, and independent R\&D investment has a masking effect between them.

Secondly, threshold test shows that the model has a single threshold. Thus, we divide the original data into two groups by the threshold variable. According to the 
results of fixed effect grouped regression, we found that the effect of the intensity of IPP on the level of GTI is opposite, which verifies the rationality of inverted U-shaped relationship.

Thirdly, for the group that does not cross the threshold, the result of grouping regression shows that the intensity of IPP significantly promotes the level of GTI. However, affected by the masking effect of independent R\&D investment, the negative effect of IPP is no longer significant after crossing the threshold value.

Last but not least, with the increase of independent R\&D investment, human capital has a significant positive impact on GTI.

Foreign enterprises and joint ventures have the first-mover advantage in the field of green technology. In this case, for domestic enterprises, the cost of technological innovation will increase with the improvement of IPP, which is not conducive to domestic GTI.

At the same time, the trade barriers against China are becoming increasingly serious under the current complex and changeable international situation. Considering all above, it is crucial to strengthen independent $R \& D$ investment in China.

Therefore, to enhance the level of regional GTI, this paper gives the following suggestions. At first, for regions with low level of IPP, they should moderately increase the intensity of local IPP to promote GTI.

Then, for regions with high level of IPP, the cost of technology introduction is higher, so they could increase government subsidies for research and development [10]. In order to reduce the inhibitory effect of high intensity of IPP on the level of GTI, they should encourage regional independent $R \& D$ investment by means of $R \& D$ tax incentives [9].

At last, for the enterprises which pursue GTI, they should not only strengthen the investment in independent $R \& D$, but also pay attention to the investment in human capital. Only by vigorously training professional and technical personnel can the enterprises promote the high-quality innovation of regional green technology in the long term.

\section{References}

1. S. Kanwar. Business Enterprise R\&D, Technological Change, and Intellectua 1 Property Protection. Economics Letters. 2007,96,120-126.

2. Dasgupta, P.; Stiglitz, J. Industrial Structure and The Nature of Innovative Activity. The Economic Journal. 1980,90,266.

3. M.C. Hu.; J.A. Mathews. China's National Innovative Capacity. Research $P$ olicy. 2008,37,1465-1479.

4. Wu, Y.H.; D. Popp;; S. Bretschneider. The Effects of Innovation Policies o $\mathrm{n}$ Business R\&D: A Cross-national Empirical Study. Economics of Innovatio $n$ \& New Technology. 2007,16,237-253.

5. Amy, J.G.; Kamal, S. 2002. Intellectual Property Rights and Foreign Direct Investment. Journal of International Economics. 2002,56,387-410.

6. Lee, K.H.; Min, B. Green R\&D for Eco-innovation and Its Impact on Carb on Emissions and Firm Performance. Journal of Cleaner Production. 2015,1 08,534-542. 
7. Yin, S.; Zhang, N.; Li, B.Z. Enhancing the Competitiveness of Multi-agent Cooperation for Green Manufacturing in China: An Empirical Study of the Measure of Green Technology Innovation Capabilities and Their Influencing Factors. Sustainable Production and Consumption. 2020,23,63-76.

8. Long, C.; Zhang, X. 2011. Cluster-based Industrialization in China: Financin $\mathrm{g}$ and Performance. Journal of International Economics. 2011,84,112-123.

9. Song, M.L.; Wang, S.H.; Zhang, H.Y. Could Environmental Regulation and R\&D Tax Incentives Affect Green Product Innovation? Journal of Cleaner Production. 2020,258,120849.

10. Yi, M.; Wang, Y.Q.; Yan, M.D. 2020. Government R\&D Subsidies, Enviro nmental Regulations, and Their Effect on Green Innovation Efficiency of $M$ anufacturing Industry: Evidence from the Yangtze River Economic Belt of China. International Journal of Environmental Research and Public Health. 2020,17.

11. Baron, R.M.; Kenny, D.A. 1986. The Moderator-mediator Variable Distincti on in Social Psychological Research: Conceptual, Strategic, and Statistical C onsiderations. Journal of Personality and Social Psychology. 1986,51,1173-1 182.

12. J.S. Ang; Cheng, Y.; Wu, C. Does Enforcement of Intellectual Property Ri ghts Matter in China? Evidence from Financing and Investment Choices in the High-Tech Industry. Review of Economics and Statistics. 2014,96,332-34 8.

13. J.A. Schumpeter. Capitalism, Socialism, and Democracy. American Economi c Review. 1942,3,594-602.

14. M. Romer; P.M. Romer. Endogenous Technological Change. Nber Working Papers. 1989,98,71-102.

15. A.F. Hayes. Beyond Baron and Kenny: Statistical Mediation Analysis in the New Millennium. Communication Monographs. 2009,76,408-420.

16. B.E. Hansen. Threshold Effects in Non-dynamic Panels: Estimation, Testing, and Inference. Journal of Econometrics. 1999,93,345-368.

17. Kwan, L.Y.Y.; Chiu, C.Y. Country Variations in Different Innovation Outpu ts: The Interactive Effect of Institutional Support and Human Capital. Journ al of Organizational Behavio. 2015,36,1050-1070.

18. Wang, H.Q.; Zhang, Y. Trade Structure Upgrading, Environmental Regulatio $\mathrm{n}$ and Green Technology Innovation in Different Regions of China. China Soft Science. 2020,350,179-186.

19. Xu, H.; Zhao, J.W. The Green Technology Advancement Effect of R\&D In vestment: Based on the Perspective of Technological Progress at the City L evel. China Population Resources and Environment. 2020,30,121-128.

20. Wang, X.; Chu, X. External Financing and Enterprises' Green Technology I nnovation: A study based on the Threshold Model of Firm Size. Systems E ngineering-Theory \& Practice. 2019,39,2027-2037.

21. Song, H.F.; Zhao, X.; Wu, J.J. Science \& Technology Innovation, Intellectu al Property development countermeasures under background of US-China tra de conflict. Bulletin of the Chinese Academy of Sciences. 2019,34,856-865.

22. Li, W. Can Intellectual Property Rights Protection and Governmental R\&D Investment Promote Chinese Enterprises' R\&D Investment? Knowledge Man agement Research \& Practice. 2017,15,551-559. 
23. Li, G.P.; Li, Y.G.; Quan, J.M. Environmental Regulation, R\&D Investment and Enterprises' Green Technological Innovation Capability. Science of Scien ce and Management of S.\& T. 2018,39,61-73.

24. Wu, C.; Yang, S.W.; Tang, P.C. Construction of the Efficiency Promotion Model of Green Innovation in China's Heavy Polluted Industries. China Po pulation Resources and Environment. 2018,28,40-48.

25. Qian, L.; Wang, W.P.; Xiao, R.Q. Research on the Regional Disparities of China's Industrial Enterprises Green Innovation Efficiency from the Perspecti ve of Shared Inputs. China Population Resources and Environment. 2018,28, 27-39.

26. Gao, N.; Yu, W.C.; Liang, P.H. Markets, Legal Environment and Regional Innovation Activities. Science Research Management. 2017,38,26-34.

27. Y. Furukawa. Intellectual Property Protection and Innovation: an inverted-U relationship. Economics Letters. 2010,109,99-101.

28. Li, J.J.; Zhuang, Z.Y. The effect of Intellectual Property Protection on Regi onal Economic Growth. Studies in Science of Science. 2017,35,557-564.

29. Yuan, B.; Liu, W.X.; Zhang, P.C. The influence of the Protection Ability o f Intellectual Property on Large Scientific Project Technology Innovation: A Contingent Model. Systems Engineering-Theory \& Practice. 2014,34,2965-2 973.

30. Wen, Z.L.; Ye, B.J. Analyses of Mediating Effects: The Development of M ethods and Models. Advances in Psychological Science. 2014,22,731-745.

31. Yi, X.Z.; Zhang, Y.B. Technology Gap, Intellectual Property Rights Protecti on, and Technology Progress of Lagging Countries. Quantitative \& Technic al Economics. 2006,23,111-121.

32. Yang, Z.N.; Li, D.H. Government Supervision, Eel Effect and Intellectual P roperty Rights Management: Enterprises' Innovation Performance Promotion. Chinese Journal of Management Science. 2010,18,177-184.

33. Liu, J.M.; Tang, H.L.; Wu, J.G. Research on the Micro Effec-t of 'Business Tax Replaced with VAT Reform' on Technological Innovation un-der the Bac kground of Enterprise Heterogeneity. China Soft Science. 2019,09,134-142.

34. Zhou, M.; Shen, W.J. Research on the Mechanism of R\&D Investment on Regional Innovation Capacity: Based on Empirical Evidence of Intellectual Property Protection Intensity. Science of Science and Management of S.\& $T$. 2018,39,26-39.

35. James, R.B.; G. Martinsson.; Bruce, C.P. What promotes R\&D? Comparativ e evidence from around the world. Research Policy. 2017,46,447-462.

36. Mukherjee, A. Patent Protection and R\&D with Endogenous Market Structu re. Journal of Industrial Economics. 2017,65,220-234.

37. Yang, L.J. Influence of Technology Import and Independent R\&D on Econ omic Growth: A Study Based on The Perspective of Intellectual Property $\mathrm{P}$ rotection. Science Research Management. 2020,41,9-16.

38. Jin, Q.H.; Yan, T.H. Research on the Relationship between Independent Re search and Regional Innovation Ability: Dynamic Threshold Effect based on the Perspective of Intellectual Property Protection. Science of Science and Management of S.\&T. 2017,38,148-157.

39. Zhang, Y.B.; Yi, X.Z.; Liu, Z.Y. Intellectual Property Rights Protection in Lagging Countries and Their Technology Catching-up. China Soft Science. 2006,007,60-67. 
40. Chu, A.C.; Cozzi, G.; Fan, H.C.; Pan, S.Y.; Zhang, M.B. Do Stronger Pate nts Stimulate or Stifle Innovation? The Crucial Role of Financial Developm ent. Journal of Money Credit and Banking. 2020,52,1305-1322. 